\title{
SOBREVIVÊNCIA DE FUNGOS ASSOCIADOS AO POTENCIAL FISIOLÓGICO DE SEMENTES DE TRITICALE (X. triticosecale Wittmack) DURANTE O ARMAZENAMENTO ${ }^{1}$
}

PRISCILA FRATIN MEDINA², MARIA APARECIDA DE SOUZA TANAKA; JOÃO JOSÉ DIAS PARISI ${ }^{2}$

\begin{abstract}
RESUMO - Sementes de triticale de um lote do cultivar IAC-2, com $85 \%$ de germinação e incidência natural de Pyricularia grisae (34.5\%), Bipolaris sorokiniana (12\%), Fusarium graminearum (15\%) e Alternaria alternata $(35 \%)$, foram armazenadas em câmara fria, a $10{ }^{\circ} \mathrm{C}$, e em local sem controle das condições do ambiente, por doze meses. O potencial fisiológico foi avaliado em intervalos bimestrais, utilizando-se os testes de germinação, de envelhecimento acelerado, de tetrazólio e de emergência de plântulas no campo; a sobrevivência dos fungos foi avaliada por meio do teste de papel de filtro. As sementes mantiveram o nível de viabilidade e de vigor e a incidência de fungos patogênicos foi pouco alterada no armazenamento a $10^{\circ} \mathrm{C}$. Em condições de ambiente não controlado, a germinação e a viabilidade das sementes armazenadas decresceram, aumentando a quantidade de sementes mortas devido à maior velocidade de deterioração e a um nível crescente de fungos de armazenamento, principalmente de Penicillium spp. Nestas condições, a incidência dos fungos patogênicos decresceu continuamente até o final do período de armazenamento, atingindo valores muito baixos; porém na época recomendada para a semeadura da cultura no Estado de São Paulo (mês de abril), a sobrevivência destes patógenos ainda comprometia a qualidade sanitária das sementes.
\end{abstract}

Termos para indexação: X. triticosecale Wittmack, sementes, armazenamento, vigor, germinação.

\section{SURVIVAL OF SEED-BORNE FUNGI ASSOCIATED TO THE PHYSIOLOGICAL QUALITY OF TRITICALE (X. triticosecale Wittmack) STORED SEEDS}

\begin{abstract}
Triticale seeds of the IAC-2 cultivar presented germination of $85 \%$ after harvest and natural incidence of the following pathogenic fungi: 34.5\% Pyricularia grisae, $12 \%$ Bipolaris sorokiniana, $15 \%$ Fusarium graminearum and $35 \%$ Alternaria alternata. The seeds were stored at $10{ }^{\circ} \mathrm{C}$ and under natural ambient conditions for twelve months. The seed physiological quality was evaluated at bimonthly intervals by the germination, accelerated aging, tetrazolium and field emergence tests and fungi survival was evaluated by the blotter test. The seeds stored at $10^{\circ} \mathrm{C}$ maintained the same level of germination, viability and vigor for twelve months even though the fungi incidences also remained almost unchanged too. The germination and viability of seeds stored under natural ambient conditions decreased and the level of dead seeds increased due to a higher speed of deterioration and an increased level of storage fungi, mainly Penicillium spp.. The pathogenic fungi levels decreased, reaching very low values at the end of the storage period. However, the pathogen survival was still harmful at the time of the planting season (April).
\end{abstract}

Index terms: X. triticosecale Wittmack, seeds, storage, vigor, germination, seed pathology.

${ }^{1}$ Submetido em 27/05/2009. Aceito para publicação em 03/09/2009.

Cep: 13001-970. Campinas, SP; e-mail: pfmedina@iac.sp.gov.br

${ }^{2}$ Eng. Agr. Pesquisadores, Instituto Agronômico (IAC); Caixa Postal 28, 


\section{INTRODUÇÃO}

O triticale (X. triticosecale Wittmack) é um cereal de inverno resultante da hibridação de duas espécies distintas, o trigo (Triticum aestivum L.) e o centeio (Secale cereale L.) que lhe conferiram qualidades panificáveis e rusticidade, respectivamente; apresenta rendimentos elevados, resistência a doenças e tolerância a solos ácidos (Baier, 1995).

No Brasil as principais áreas produtoras de triticale estão localizadas nas regiões Sul, Centro Oeste e Sudeste (Martins et al., 2004), em áreas marginais às dos cultivos de cereais de inverno pois, devido à qualidade panificativa inferior, passou a ser direcionado à alimentação animal, principalmente na forma de forragem verde, feno, silagem, planta inteira ou de grão úmido, grãos secos para rações, bem como na cobertura vegetal para proteção do solo e adubação verde (Baier et al., 1994).

Em São Paulo, na região sul do estado, o triticale constitui-se em alternativa à cultura do trigo, devido à boa produtividade e pela rusticidade que acarretam um menor custo de produção em conseqüência da ausência de pulverização com fungicidas (Martins et al., 2004).

Apesar destas vantagens, o triticale tem apresentado alguns problemas, entre eles a germinação na espiga e o baixo vigor inicial de desenvolvimento das plantas (Baier e Nedel, 1985). De acordo com Rocha et al. (1998), fatores envolvidos na formação das sementes de triticale podem estar relacionados ao vigor inferior das mesmas, quando comparadas com o das espécies que lhe deram origem. A alta atividade das enzimas $\alpha$-amilase e hidrolases do tipo fosfatases ácidas, nesta fase, resultam na redução da massa e no enrugamento das sementes. Por essa razão, a avaliação do vigor das sementes dessa espécie deve ser considerada como prática rotineira necessária para estimar o potencial fisiológico dos lotes de sementes no estabelecimento das plantas no campo.

As sementes de triticale podem, ainda, ser invadidas por patógenos, desde a sua formação, durante o seu desenvolvimento e, também, após a colheita, no armazenamento, com influências na viabilidade e no potencial de transmissão de doenças.

A transmissão de patógenos pelas sementes deve ser avaliada sob dois aspectos gerais, uma vez que os danos causados são variáveis. Alguns patógenos provocam perdas no campo, com efeitos restritos à redução de rendimento, sem afetar a viabilidade da semente. Outros patógenos se caracterizam por, além de prejudicar o rendimento, causar redução na germinação e no vigor das sementes, com reflexos negativos na aprovação de lotes e, consequentemente, na disponibilidade desse insumo para a semeadura seguinte (Lucca-Filho, 1985).

$\mathrm{O}$ triticale é suscetível às doenças como a helmintosporiose (mancha marrom) e à fusariose (Baier e Nedel, 1985), causadas por patógenos veiculados por sementes, que as invadem ainda no campo e requerem, para seu crescimento, umidade relativa do ar em torno de $90-95 \%$. O tempo de sobrevivência desses fungos nas sementes está diretamente relacionado às condições do ambiente de armazenamento (Lal e Kapoor, 1979; Berjak, 1987; Carvalho e Nakagawa, 2000).

Bipolaris sorokiniana (Sacc.) Shoem. (sin. Helminthosporium sativum Pamm., King \& Bakke) é o agente causal da helmintosporiose, associada à podridãocomum-das-raízes e a manchas foliares, e constitui-se no principal patógeno encontrado nas sementes de triticale (Reis, 1988); sobrevive de uma safra para outra, tanto nas sementes quanto nos restos de cultura de trigo, de triticale e de centeio, entre outras espécies (Oliveira e Baier, 1993). Lotes de sementes com níveis de infecção de B. sorokiniana entre 10 e $40 \%$ podem ser tratados com fungicidas; entretanto, se ocorrerem infecções superiores a $40 \%$ o lote deve ser eliminado pois, neste caso, a eficiência dos produtos é reduzida (reunião da comissão Centro-Sul Brasileira de pesquisa de trigo e triticale, 2004).

A fusariose é a mais importante dentre as doenças da espiga pelos prejuízos ao rendimento e à qualidade das sementes ou grãos. É causada pelo fungo Fusarium graminearum Schwabe, cuja forma telemórfica é a Giberella zeae (Schwein) Petch, possui muitos hospedeiros sendo que em triticale, em trigo e em centeio, a infecção ocorre através das anteras, durante a floração (Reis, 1990).

Alternaria alternata ((Fr.:Fr) Keissler (sin. Alternaria tenuis Nees), juntamente com outros fungos como B. sorokiniana, Cladosporium sp., Curvularia lunata e Fusarium sp., está associado à sintomatologia conhecida como ponta negra ("blak point"). As sementes infectadas apresentam áreas de tonalidade marrom escuro, principalmente próximo ao embrião. A presença desses fungos pode provocar podridão de sementes e reduzir significativamente a emergência (Mathur e Cunfer, 1993).

Triticale é, também, o mais novo hospedeiro de Pyricularia grisea (Cooke) Sacc., agente causal da brusone, no Estado de São Paulo. Extensas áreas da cultura, no sul 
do Estado sofreram severas perdas no ano de 2001. Martins et al. (2004) constataram a importância da semente como fonte primária dessa doença ao verificarem a possibilidade de transmissão de sementes para plântulas; assim, foi inferido que o patógeno pode ter sido introduzido nesta região por meio de sementes contaminadas, oriundas do Paraná onde foi relatada a primeira ocorrência da doença (Mehta e Baier, 1998).

As doenças da espiga, como a fusariose e a brusone são de difícil controle com fungicidas e, no entanto, são as que, em geral, causam maiores prejuízos à cultura do triticale (reunião da comissão Centro-Sul Brasileira de pesquisa de trigo e triticale, 2004).

Os fungos de armazenamento, por sua vez, estão presentes nas sementes recém-colhidas, geralmente em porcentagens muito baixas. São capazes de sobreviver em ambientes com baixa umidade relativa do ar, proliferando-se em sucessão aos fungos de campo e causando a deterioração das sementes. Os mais freqüentes geralmente são Aspergillus spp. e Penicillium spp. (Tuite et al., 1985).

É relativamente vasta a literatura disponível sobre a natureza dos fungos de armazenamento e os danos provocados por eles em sementes de milho e de trigo. No entanto, pouco é conhecido a respeito do comportamento dos fungos fitopatogênicos (de campo) nas sementes de triticale armazenadas, principalmente se conservadas em diferentes condições de ambiente, as quais podem afetar diretamente a sobrevivência desses fungos (Lal e Kapoor, 1979; Meronuck, 1987).

Também não há informações na literatura sobre o potencial fisiológico de sementes de triticale infectadas por fungos patogênicos.

Visando aumentar as informações sobre este assunto, o objetivo do trabalho foi avaliar o potencial fisiológico de sementes de triticale, bem como a sobrevivência de fungos associados a elas, durante doze meses de armazenamento em câmara fria e em ambiente sem controle de suas condições.

\section{MATERIAL E MÉTODOS}

A pesquisa foi realizada de outubro de 2002 a outubro de 2003, no Centro de Fitossanidade e no Laboratório de Análise de Sementes do Instituto Agronômico do Estado de São Paulo (IAC), em Campinas-SP, localizado a uma altitude de $674 \mathrm{~m}$, a $22^{\circ} 54^{\prime}$ de latitude sul e a $47^{\circ} 05^{\prime}$ 'de longitude a oeste de Greenwich.
Foram utilizadas sementes de triticale (X. triticosecale Wittmack), cultivar IAC-2, de um lote de sementes básicas, produzido em Campinas, com germinação de $85 \%$ e, portanto, superior à mínima estabelecida pelos padrões para comercialização de sementes (Brasil, 2005). O lote foi escolhido devido à incidência natural e simultânea de importantes fungos de campo como Pyricularia grisea (34,5\%), Bipolaris sorokiniana (12,0\%), Fusarium graminearum (28,5\%) e Alternaria alternata (35,0\%).

Dez $\mathrm{kg}$ de sementes foram homogeneizados e subdivididos em dez repetições de um $\mathrm{kg}$, cada uma das quais acondicionadas em embalagens permeáveis (sacos de papel Kraft) para que o teor de água das sementes atingisse o equilíbrio com a umidade relativa do ar dos ambientes de armazenamento. Em seguida, cinco repetições foram armazenadas em câmara fria e seca, a $10{ }^{\circ} \mathrm{C}$ e umidade relativa do ar de $30 \%$, e as outras cinco em laboratório sem controle das condições do ambiente durante todo o período experimental.

Os dados de umidade relativa do ar e de temperaturas máxima, média e mínima, registrados por termohigrógrafo durante o armazenamento das sementes, no Centro Experimental de Campinas onde se localiza o laboratório, são dispostos na Figura 1.

No início e, posteriormente, em intervalos bimestrais do período de 12 meses de armazenamento (outubro e dezembro de 2002 e fevereiro, abril, junho, agosto e outubro de 2003), foram realizados os seguintes testes:

Grau de umidade - o grau de umidade foi determinado pelo método da estufa, a $105 \pm 3{ }^{\circ} \mathrm{C}$, por 24 horas, em amostras de $5 \mathrm{~g}$ para cada repetição, segundo as instruções das Regras para Análise de Sementes (Brasil,1992).

Germinação - o teste de germinação foi realizado com uma amostra de 50 sementes por repetição, distribuída em rolos de papel toalha germitest, à temperatura de $20^{\circ} \mathrm{C}$. O volume de água para embebição foi 2,5 vezes a massa do substrato seco. As avaliações foram realizadas aos quatro e oito dias após a semeadura, de acordo com as instruções das Regras para Análise de Sementes - RAS (Brasil, 1992);

Tetrazólio - a viabilidade mediante o teste de tetrazólio foi avaliada com uma amostra de 50 sementes por repetição, pré-condicionada em papel toalha umedecido e mantida a $30{ }^{\circ} \mathrm{C}$ em ambiente úmido, durante 16 horas. Decorrido este período, as sementes foram bisseccionadas longitudinalmente através do embrião, imersas em solução de sal de tetrazólio a 0,075\% (cloreto de 2,3,5 trifenil tetrazólio) e mantidas, protegidas da luz, durante 2 horas a $40{ }^{\circ} \mathrm{C}$. Em seguida, foram lavadas e avaliadas. 

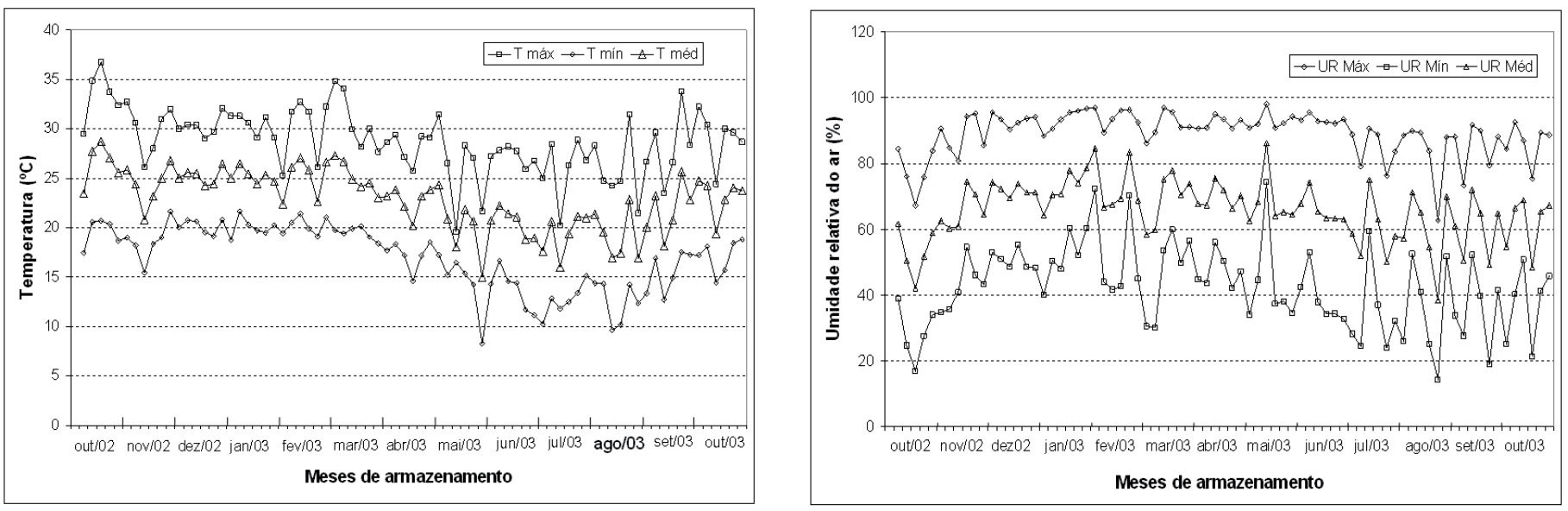

FIGURA 1. Dados de temperaturas máxima ( $T$ máx), média ( $T$ méd) e mínima ( $T$ mín) e de umidades relativas do ar máxima (UR Máx), média (UR Méd) e mínima (UR mín) observados no Centro Experimental em Campinas - SP, 2003, durante o armazenamento das sementes de triticale.

Envelhecimento acelerado - o teste de envelhecimento acelerado foi realizado com uma amostra de aproximadamente nove gramas de sementes por repetição, em caixas plásticas $(11 \times 11 \times 3,5 \mathrm{~cm})$ como compartimento individual (minicâmaras), possuindo no seu interior uma bandeja de tela metálica, onde foram distribuídas as sementes, de maneira a formarem camada simples. Foram adicionados $40 \mathrm{~mL}$ de água ao fundo de cada caixa e estas foram tampadas, obtendose assim cerca de $100 \%$ de UR em seu interior; essas caixas, assim preparadas, foram mantidas a $41{ }^{\circ} \mathrm{C}$, durante 63 horas. Em seguida, uma amostra de 50 sementes de cada repetição foi submetida ao teste de germinação conforme já descrito. A contagem foi realizada aos quatro dias após a semeadura e os resultados expressos em percentagem média de plântulas normais.

Emergência de plântulas em campo - a emergência de plântulas em campo foi executada com uma amostra de 50 sementes para cada repetição. As sementes de cada amostra foram distribuídas em sulcos de $1,00 \mathrm{~m}$ de comprimento e, $0,07 \mathrm{~m}$ de profundidade, espaçados de $0,20 \mathrm{~m}$, cobertos com uma camada de $0,02 \mathrm{~m}$ de terra; o espaçamento entre as sementes nos sulcos foi de $0,02 \mathrm{~m}$. A contagem do número de plantas emersas foi efetuada aos quinze dias após a semeadura e, os dados, expressos em percentagem.

Sanidade - o teste de sanidade foi realizado pelo método do papel de filtro com congelamento empregandose uma amostra de 50 sementes por repetição (Reis e Casa, 1998). As sementes foram distribuídas, equidistantes entre si, sobre três folhas de papel de filtro umedecidas com água destilada esterilizada, contidas em placas de Petri de plástico transparente, de $9 \mathrm{~cm}$ de diâmetro. Em cada placa foram colocadas 25 sementes. A seguir, foram incubadas em sala com temperatura de $20 \pm 2{ }^{\circ} \mathrm{C}$, em regime intermitente de 12 horas de luz fluorescente branca de 40w, e 12 horas de escuro, durante 24 horas. A luz foi fornecida por tubos de $120 \mathrm{~cm}$ de comprimento, dispostos paralelamente, distantes $20 \mathrm{~cm}$ um do outro e $40 \mathrm{~cm}$ acima das placas. Em seguida, as sementes foram submetidas ao congelamento, a $-20{ }^{\circ} \mathrm{C}$, durante 24 horas, e transferidas, após esse período, à sala de incubação onde permaneceram durante mais cinco dias. As avaliações foram realizadas pelo exame individual de cada semente em estereomicroscópio e, quando necessária, a identificação dos fungos foi confirmada pela observação de lâminas em microscópio composto e consulta à literatura pertinente (Mathur e Cunfer, 1993; Reis e Casa, 1998).

O delineamento experimental adotado foi o inteiramente casualizado em esquema de parcelas subdivididas no tempo, com cinco repetições. A análise de variância foi efetuada utilizando-se o Programa de Análise Estatística - Sanest (Zonta \& Machado, 1987). Para a comparação das médias de ambientes de armazenamento foi utilizado o Teste de Tukey $(\mathrm{p} \leq 0,05)$ e para a comparação das médias de épocas de armazenamento, a regressão polinomial e o Teste de Tukey.

\section{RESULTADOS E DISCUSSÃO}

Os teores de água das sementes armazenadas no ambiente não controlado (laboratório) foram mais elevados durante o período entre dezembro de 2002 e abril de 2003 (Tabela 1), em equilíbrio com a umidade relativa do ar mais elevada neste período, coincidente com temperaturas também mais altas, com as máximas, em geral, superiores 
a $30{ }^{\circ} \mathrm{C}$ (Figura 1). Com a redução da umidade relativa do ar, a partir de maio/junho, o teor de água das sementes também se reduziu. Este fato, aliado às temperaturas mais baixas, caracterizou este período como o mais favorável à preservação do potencial fisiológico das sementes. Deste modo as sementes armazenadas nestas condições tiveram redução da capacidade germinativa (Figura 2A), segundo uma função linear, em razão do aumento, também linear, nos índices de sementes mortas (Figura 2C), com elevado coeficiente de determinação $(0,84)$. Porém, conforme o teste de Tukey foi verificado, no mês de abril, redução mais acentuada da porcentagem de germinação (Figura 2A), em consequência da maior porcentagem de sementes mortas (Figura 2C), coincidindo com o final do período quente e úmido (Figura 1); a partir de então a velocidade de deterioração se reduziu até o final do armazenamento (Figura 2A), em função de esta época ter sido mais seca e com temperaturas mais baixas (Figura 1).

TABELA 1. Grau de umidade (\%) de sementes de triticale (Triticosecale Wittmack), cultivar IAC-2, armazenadas durante 12 meses em câmara fria e seca, a $10{ }^{\circ} \mathrm{C}$ e $30 \%$ de umidade relativa do ar, e em laboratório, sem controle das condições do ambiente.

\begin{tabular}{clllllll}
\hline \multirow{2}{*}{ Local } & \multicolumn{7}{c}{ Meses de armazenamento } \\
\cline { 2 - 8 } & Out (0) & Dez (2) & Fev (4) & Abr (6) & Jun (8) & Ago (10) & Out (12) \\
\hline Câmara Fria & 12,6 & 12,1 & 12,3 & 12,1 & 11,9 & 11,1 & 11,9 \\
Laboratório & 12,6 & 13,0 & 13,2 & 12,9 & 12,1 & 11,7 & 11,6 \\
\hline
\end{tabular}
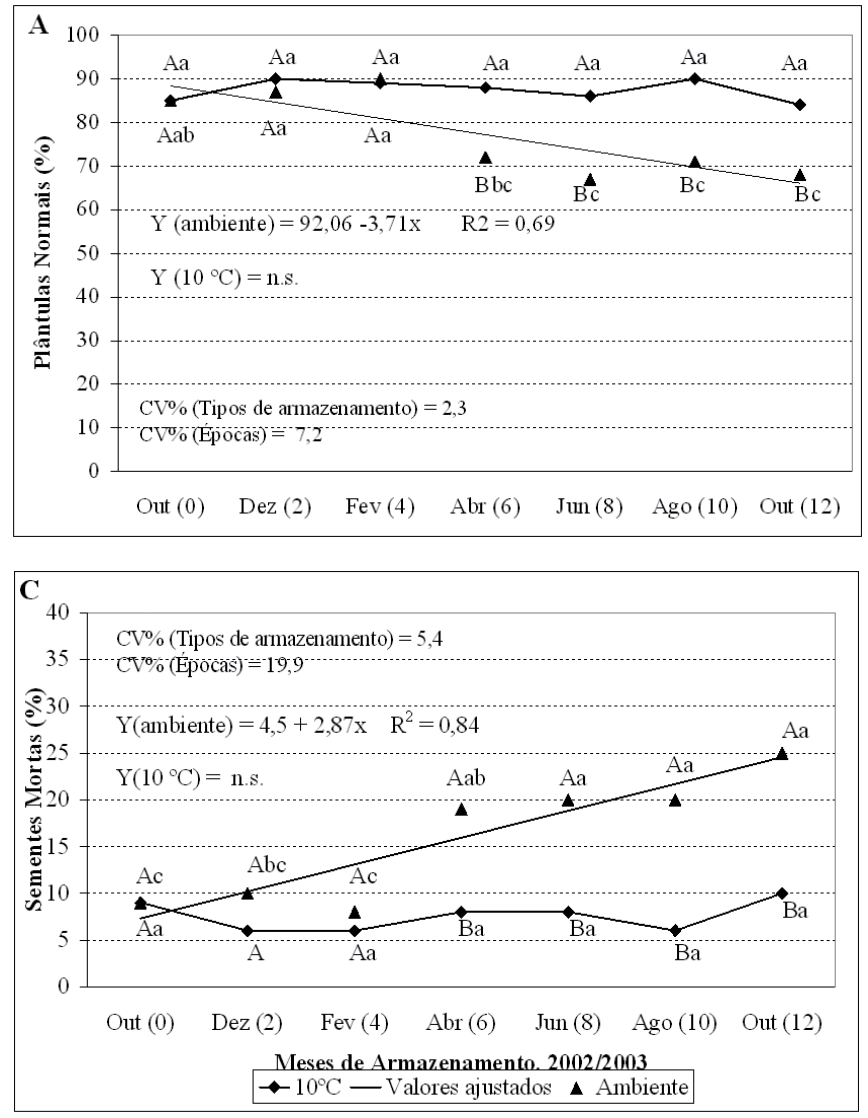
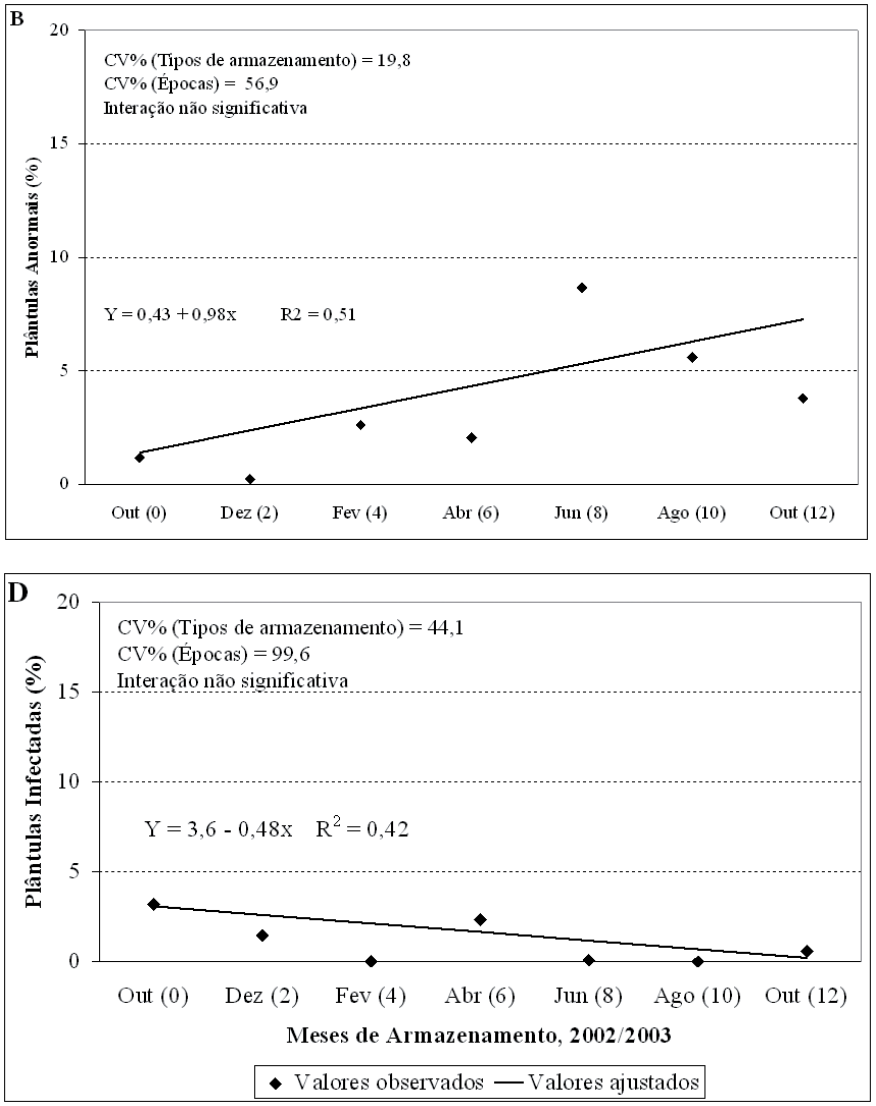

FIGURA 2. Valores médios de plântulas normais (A), anormais (B), sementes mortas (C) e de plântulas infeccionadas (D), do teste de germinação, em função do armazenamento em câmara fria, a $10{ }^{\circ} \mathrm{C}$, e em laboratório, sem controle das condições do ambiente, durante 12 meses. Médias seguidas pela mesma letra maiúscula, entre ambientes de armazenamento, e minúscula, entre épocas de armazenamento, não diferiram a 5\% pelo Teste de Tukey. 
Pela conhecida "Regra de Harrington", o período seguro de o armazenamento das sementes ortodoxas duplica para cada redução de $1 \%$ no grau de umidade das sementes (base úmida), dentro do limite de 5 a $14 \%$, ou decréscimo de 5,5 ${ }^{\circ} \mathrm{C}$ na temperatura ambiente, dentro do limite de 0 a $50{ }^{\circ} \mathrm{C}$; ambas as reduções efetuadas simultaneamente têm efeitos aditivos (Harrington, 1972).

Quando armazenadas em câmara fria, além da temperatura mais baixa, de $10{ }^{\circ} \mathrm{C}$, ter sido mais favorável à manutenção da qualidade, o teor de água das sementes foi de 0,8 a 0,9 pontos percentuais inferiores (Tabela 1) nos períodos mais úmidos, entre dezembro e abril (Figura 2A), em comparação ao armazenamento em ambiente não controlado. Desta forma, sementes de triticale, embora geneticamente menos vigorosas do que as das espécies que lhe deram origem (Rocha et al. 1998), quando armazenadas nestas condições mantiveram porcentagens de germinação (Figura 2A), bem como a de sementes mortas (Figura $2 \mathrm{C}$ ), praticamente inalteradas durante todo o período de armazenamento.

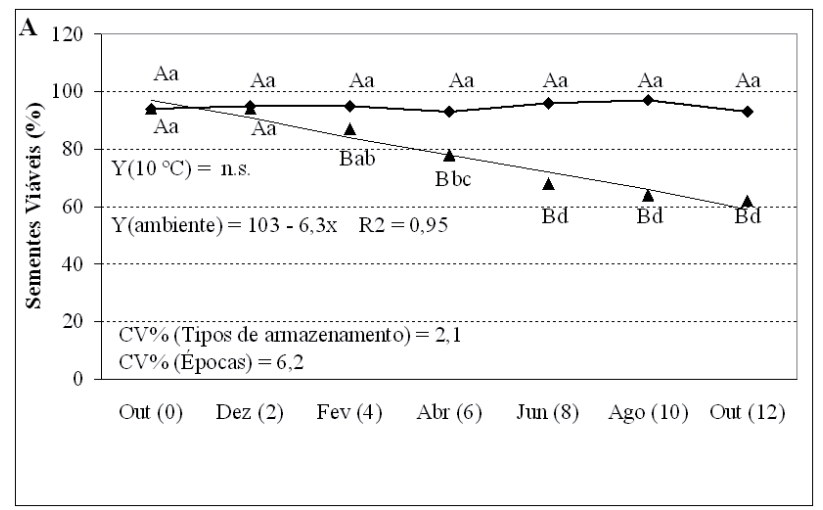

Nas duas condições de armazenamento, pela análise estatística, não se constatou interação significativa para porcentagens de plântulas anormais (Figura 2B) e de plântulas infectadas (Figura 2D), com valores reduzidos por todo o período. A incidência de plântulas infectadas diminuiu com o tempo de armazenamento, simultaneamente à redução da incidência dos fungos (Figura 4), fato revelador da baixa transmissão destes pelas sementes.

Os resultados verificados nos testes de envelhecimento acelerado (Figura 3B) e de emergência de plântulas em campo (Figura 3C) demonstraram preservação do vigor das sementes de triticale durante os doze meses de armazenamento a $10{ }^{\circ} \mathrm{C}$ e umidade relativa do ar de $30 \%$, mas redução em ambiente não controlado. A estabilização do potencial fisiológico das sementes armazenadas em ambiente não controlado a partir do mês de junho de 2003, identificada pelo teste de germinação, foi ainda mais evidenciada pelos testes de vigor, uma vez que no processo de deterioração a queda do vigor precede à da germinação (Delouche e Baskin, 1973).

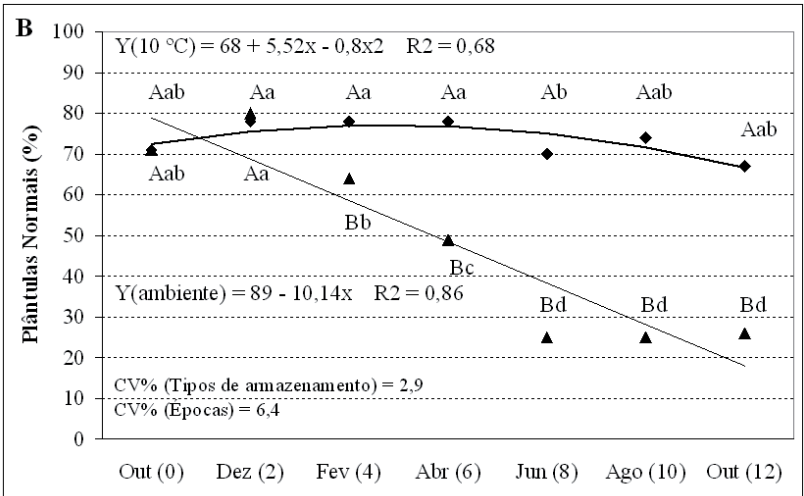

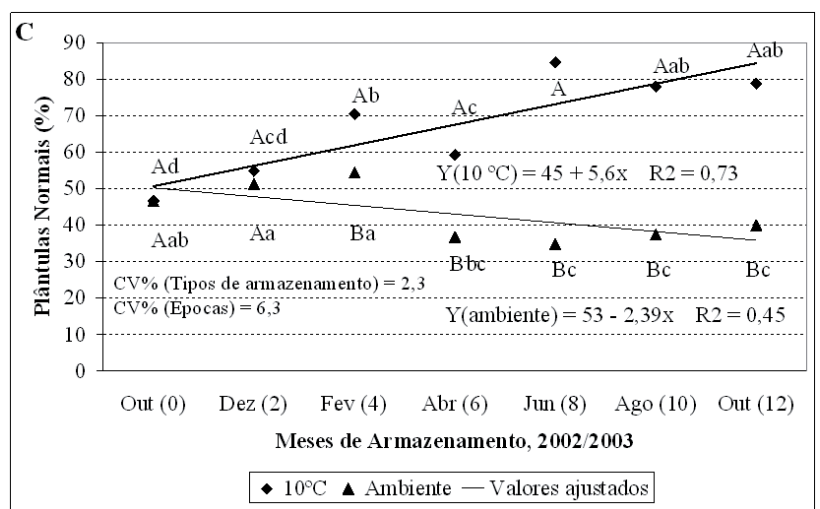

FIGURA 3. Valores médios de sementes viáveis no teste de tetrazólio (A), de plântulas normais nos testes de envelhecimento acelerado (B) e de emergência de plântulas em campo (C), em função do armazenamento em câmara fria e seca, a $10{ }^{\circ} \mathrm{C}$ e $30 \%$ de umidade relativa do ar, e em laboratório, sem controle das condições do ambiente, durante 12 meses. Médias seguidas pela mesma letra maiúscula, entre ambientes de armazenamento, e minúscula, entre épocas de armazenamento, não diferiram a $5 \%$ pelo Teste de Tukey. 

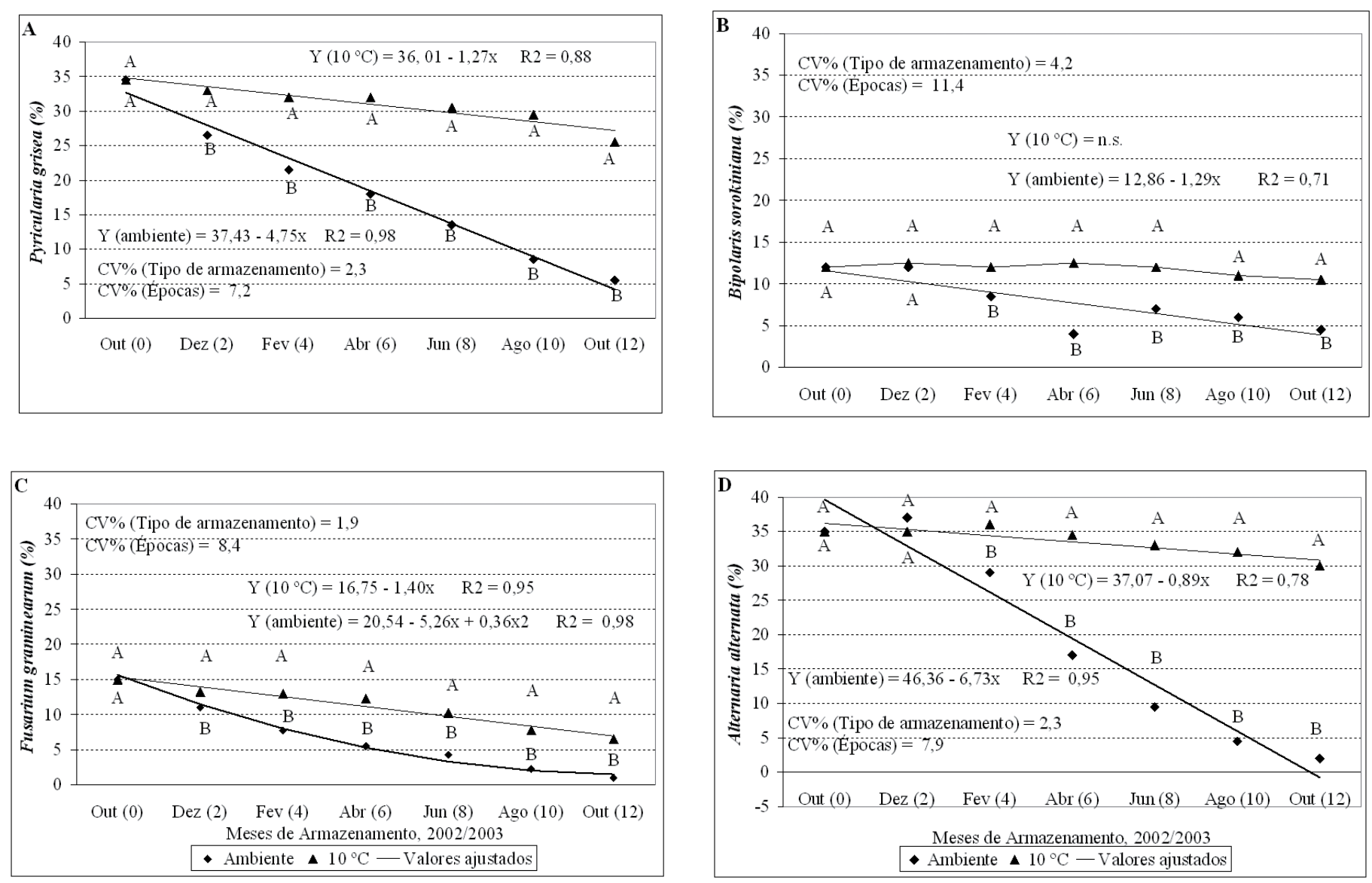

FIGURA 4. Valores médios de incidências dos fungos: Pyricularia grisea (A), Bipolaris sorokiniana (B), Fusarium graminearum (C) e Alternaria alternata (D) em sementes de triticale armazenadas em câmara fria e seca, a $10{ }^{\circ} \mathrm{C}$ e $30 \%$ de umidade relativa do ar, e em laboratório, sem controle das condições do ambiente, durante doze meses. Médias seguidas pela mesma letra maiúscula, entre ambientes de armazenamento, não diferiram a $5 \%$ pelo Teste de Tukey.

O teste de tetrazólio (Figura 3A) confirmou os resultados obtidos no teste de germinação (Figura 2A); foi observada, no entanto, redução dos valores de viabilidade mais constante durante o armazenamento em condições não controladas, com coeficiente de determinação da função linear de 0,95.

As mesmas condições que contribuíram para a manutenção do potencial fisiológico elevado das sementes na câmara fria também foram favoráveis à preservação dos fungos de campo, em comparação ao ambiente não controlado (Figura 4), com comprometimento da qualidade sanitária das sementes, conforme também verificado por Oliveira et al. (1997) em sementes de milho.

A viabilidade de Bipolaris sorokiniana foi mantida praticamente inalterada a $10^{\circ} \mathrm{C}$ e $30 \%$ de umidade relativa do ar (Figura 4B), enquanto que as de Pyricularia grisea (Figura 4A), de Fusarium graminearum (Figura 4C) e de Alternaria alternata (Figura 4D) reduziram-se linearmente, de modo pouco pronunciado, de 5 a 10 pontos percentuais até o final do armazenamento, com coeficientes de determinação elevados, entre 0,78 e 0,95. No ambiente não controlado foi observada redução da incidência desses fungos, ao longo do armazenamento por 12 meses, a índices de 0 a 5\% (Figura 4). No entanto, se considerada a época de semeadura do triticale, abril/2003, as sementes, embora com porcentagem de germinação (Figura 2A) em conformidade com os padrões de comercialização (Brasil, 2005), tinham (a) incidências de fungos, principalmente de $P$. grisea e de A. alternata, consideravelmente elevadas, superiores a $15 \%$, enquanto as de $B$. sorokiniana e de Fusarium graminearum superiores a $5 \%$. O fato revela comprometimento da qualidade sanitária dessas sementes, nesta ocasião, ainda mais por B. sorokiniana constituir-se no principal patógeno encontrado nas sementes de triticale e de outros cereais de inverno, com sobrevivência, de uma safra para outra, quando associado às sementes ou presente 
em restos de cultura (Reis, 1988; Oliveira e Baier, 1993).

Devido à sobrevivência de $B$. sorokiniana, de $F$. graminearum e de $P$. grisea em sementes infectadas (Reis, 1988; Oliveira; Baier, 1993; Mehta e Baier, 1998; Martins et al, 2004), pode haver transmissão desses patógenos para as plantas e estas, desta forma, consistirem em focos de infecção primária. Este fato é agravado por causarem doenças de difícil controle (reunião da comissão Centro-Sul Brasileira de pesquisa de trigo e triticale, 2004), razão para o tratamento de sementes constituírem medidas preventivas para evitar, assim, a contaminação de áreas sadias, conforme já constatado recentemente com Pyricularia grisea na cultura de triticale (Martins et al., 2004).

A incidência de fungos patogênicos, todavia, não interferiu, praticamente, na germinação das sementes uma vez que a porcentagem de plântulas infectadas (Figura 2 D), observadas no teste de germinação, foi muito baixa durante todo o período experimental, tanto para as sementes armazenadas em câmara fria quanto em ambiente não controlado. Além disso, a viabilidade avaliada pelo teste de tetrazólio ao longo do armazenamento (Figura 3A) foi similar à obtida no teste de germinação (Figura 2A), com valores numéricos ligeiramente mais elevados; diferenças de até $5 \%$ entre os resultados de ambos os testes são aceitáveis, mas em sementes infectadas por fungos, como no caso do lote de sementes de triticale empregado, diferenças superiores a estas com valores numéricos maiores para o teste de tetrazólio podem ocorrer (Dias e Barros, 1999). Foi constatada, ainda, que estas diferenças em pontos percentuais foram inferiores às percentagens de sementes que apresentaram incidência de fungos patogênicos, mesmo de $F$. graminearum que sabidamente costuma ser prejudicial à germinação e ao vigor de sementes de outras culturas de cereais de inverno, como o trigo (Tuite et al. 1990).

Os níveis consideráveis de incidência de fungos patogênicos também não interferiram no vigor das sementes armazenadas a $10{ }^{\circ} \mathrm{C}$ e $30 \%$ de umidade relativa do ar, conforme os resultados obtidos nos testes de envelhecimento acelerado (Figura 3B) e de emergência de plântulas no campo (Figura 3C).

Os fungos de armazenamento não foram detectados, inicialmente, nas sementes de triticale. Incidência ínfima de Aspergillus spp., a partir do mês de abril de 2003, foi observada apenas nas sementes armazenadas em ambiente não controlado (Figura 5A), enquanto a de Penicillium spp. foi detectada nas sementes armazenadas em câmara fria apenas a partir do mês de abril de 2003, e cresceu de forma linear, mas com valores ainda bem reduzidos ao final do armazenamento que pouco afetaram a porcentagem de sementes mortas (Figura 5B). Por outro lado, nas sementes armazenadas em ambiente não controlado, este fungo ocorreu inicialmente a partir do mês de dezembro, e aumentou seguindo uma função quadrática cujo coeficiente de determinação foi próximo a um; sua incidência elevouse com maior intensidade, principalmente a partir do mês de abril de 2003, que provocou maior deterioração às sementes, coincidente com o aumento de sementes mortas.
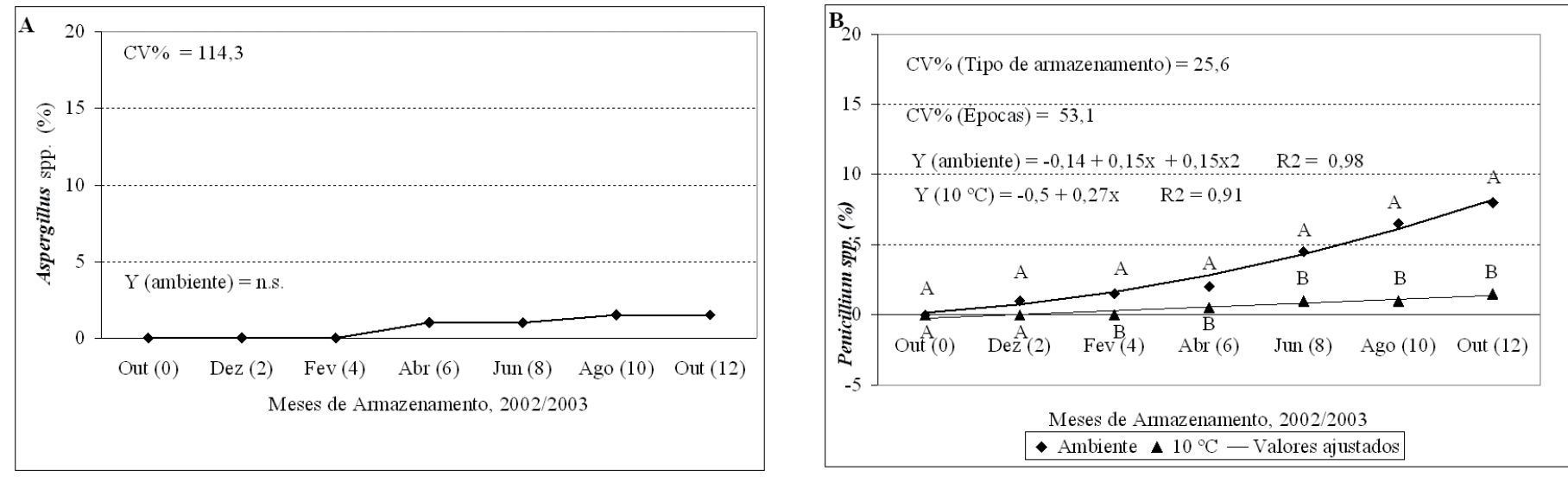

FIGURA 5. Valores médios de incidências dos fungos de armazenamento Penicillium spp. (A) e Aspergillus spp.(B) em sementes de triticale armazenadas em câmara fria e seca, a $10{ }^{\circ} \mathrm{C}$ e $30 \%$ de umidade relativa do ar, e em laboratório, sem controle das condições do ambiente, durante doze meses. Médias seguidas pela mesma letra maiúscula, entre ambientes de armazenamento, não diferiram a 5\% pelo Teste de Tukey. 
As baixas ocorrências de Penicillium spp. e de Aspergillus spp. nos dois ambientes de armazenamento podem ser atribuídas aos teores de água das sementes, em geral inferiores a $13 \%$, e, portanto, desfavoráveis ao crescimento desses fungos, de acordo com Christensen (1972).

Cladosporium herbarum e Epicocum purpurascens (Tabela 2) foram encontrados em mais de $50 \%$ das sementes analisadas, com incidências mais reduzidas nas sementes ao longo do armazenamento em ambiente não controlado. Além desses, foram detectados Curvularia lunata e Phoma spp, fungos que também não afetaram a viabilidade e o vigor das sementes (Figuras 2 e 3 ) e fazem parte do complexo de patógenos causadores de manchas de grãos comumente associados às sementes de cereais de inverno (Mathur e Cunfer,1993; Reis e Casa, 1998).

TABELA 2. Incidência (\%) de fungos em sementes de triticale (Triticosecale Wittmack) armazenadas durante 12 meses em câmara fria e seca, a $10{ }^{\circ} \mathrm{C}$ e $30 \%$ de umidade relativa do ar, e em laboratório, sem controle das condições do ambiente.

\begin{tabular}{|c|c|c|c|c|c|c|c|c|}
\hline \multirow{2}{*}{ Fungos } & \multirow{2}{*}{ Local } & \multicolumn{7}{|c|}{ Meses de armazenamento } \\
\hline & & Out (0) & $\operatorname{Dez}(2)$ & Fev (4) & Abr (6) & Jun (8) & Ago (10) & Out (12) \\
\hline \multirow[t]{2}{*}{ Cladosporium herbarum } & Câmara Fria & 59,5 & 54,0 & 52,0 & 51,5 & 49,0 & 47,0 & 44,0 \\
\hline & Laboratório & 59,5 & 49,5 & 33,0 & 28,0 & 19,5 & 10,0 & 4,0 \\
\hline \multirow[t]{2}{*}{ Curvularia lunata } & Câmara Fria & 0,0 & 0,0 & 0,0 & 0,0 & 0,0 & 0,0 & 0,0 \\
\hline & Laboratório & 0,0 & 0,0 & 0,0 & 0,5 & 1,0 & 1,5 & 1,0 \\
\hline \multirow[t]{2}{*}{ Epicoccum purpurascens } & Câmara Fria & 50,5 & 38,0 & 39,0 & 38,0 & 35,0 & 31,0 & 31,5 \\
\hline & Laboratório & 50,5 & 40,0 & 19,0 & 6,5 & 3,0 & 1,5 & 1,0 \\
\hline \multirow[t]{2}{*}{ Phoma spp. } & Câmara Fria & 2,5 & 1,5 & 1,0 & 5,0 & 4,0 & 3,0 & 3,5 \\
\hline & Laboratório & 2,5 & 0,5 & 1,0 & 2,0 & 2,0 & 2,5 & 4,0 \\
\hline
\end{tabular}

Embora os resultados tenham indicado ausência de efeito dos fungos encontrados nas sementes na incidência de plântulas infeccionadas, não é prudente relevar, no entanto, o papel das sementes infectadas na epidemiologia das doenças causadas pelos referidos patógenos. A associação com as sementes é muito importante para a continuidade do ciclo de vida dos patógenos, pois lhes são fornecidos os nutrientes necessários ao seu crescimento e garante a sua introdução na cultura já nos primeiros estádios de desenvolvimento das plantas. Ao atingir os órgãos aéreos, são facilmente disseminados pelo vento ou respingos de chuva e originam novos focos das doenças (Reis, 1990; Mathur e Cunfer, 1993; Reis e Casa, 1998).

\section{CONCLUSÕES}

Sementes de triticale têm capacidade de manter potencial fisiológico inicial, durante doze meses, de armazenamento em câmara fria e seca $\left(10{ }^{\circ} \mathrm{C}\right.$ e $30 \%$ de umidade relativa do ar) ou de maneira satisfatória por seis meses em local sem controle das condições do ambiente, em regiões com clima semelhante ao de Campinas SP. Todavia, há risco de comprometimento da qualidade sanitária das sementes em razão da sobrevivência de patógenos importantes para a cultura durante esse período.

\section{REFERÊNCIAS}

BAIER, A.C.; NEDEL, J.L.; REIS, E.M.; WIETHÖLTER, S. Triticale: cultivo e aproveitamento. Passo Fundo: EMBRAPA. Centro Nacional de Pesquisa de Trigo, 1994. 72p. (EMBRAPA-CNPT. Documentos, 19).

BAIER, A.C. Potencial de triticale no Brasil. In: REUNIÃO BRASILEIRA DE TRITICALE, 4., 1992, Chapecó. Anais... Chapecó: EPAGRI, 1995. p.8-23.

BAIER, A.C.; NEDEL, J.L. Potencial do triticale no Brasil. Pesquisa Agropecuária Brasileira, v.20, n.1, p.57-67, 1985.

BERJAK, P. Stored seeds: the problems caused by microorganisms. In ADVANCED INTERNATIONAL COURSE ON SEED PATHOLOGY, Passo Fundo, 1987. 
Proceedings...Passo Fundo: EMBRAPA; ABRATES, 1987. p.93-112.

BRASIL. Diário Oficial da União. Padrões para comercialização de sementes de triticale. Brasília, DF, 20/12/2005, nº 243, Seção 1, p.25-26.

BRASIL. Ministério da Agricultura e Reforma Agrária. Secretaria Nacional de Defesa Agropecuária. Departamento Nacional de Produção Vegetal. Coordenação de Laboratório Vegetal. Regras para Análise de Sementes. Brasília, DF, 1992. 365 p.

CARVALHO, N.M.; NAKAGAWA, J. Sementes: ciência, tecnologia e produção. 4. ed. Jaboticabal: Funep, 2000. 588 p.

CRISTENSEN, C.M. Microflora and seed deterioration. In: ROBERTS, E.H. (Ed.). Viability of Seeds. Syracuse, USA, Syracuse Univ. Press, 1972. p.59-93.

DELOUCHE, J.C.; BASKIN, C.C. Accelerated aging techniques for predicting the relative storabilityof seed lots. Seed Science and Technology, v.1, n.2, p.427-552, 1973.

DIAS, M.C.L.L.; BARROS, A.S.R.. Metodologia do teste de tetrazólio em sementes de milho. In: KRZYZANOWSKI, F.C.; VIEIRA, R.D.; FRANÇA NETO, J.B. (Ed.). Vigor de Sementes: conceitos e Testes. Londrina: ABRATES Associação Brasileira de Tecnologia de Sementes, Comitê de Vigor de Sementes, p. 8.4 1-8.4 10, 1999.

HARRINGTON, J.F. Seed storage and longevity. In: KOZLOWSKI, T.T., (Ed.). Seed Biology, New York: Academic Press, 1972. v.3.p.145-245.

LAL, S.P., KAPOOR, J.N. Succession of fungi in wheat and maize during storage. Indian Phytopathology, New Dehli, v.32, n.1, p.101-104, 1979.

LUCCA-FILHO, O.A. Importância da sanidade na produção de sementes de alta qualidade. Revista Brasileira de Sementes, v.7, n.1, p.113-123, 1985.

MARTINS, T.D.; LAVORENTI, N.; URASHIMA, A.S. Comparação entre métodos de avaliação de transmissão de Pyricularia grisea através de sementes de triticale. Fitopatologia Brasileira, v. 29, n. 4, p.425-428, 2004.

MATHUR, S.B.; CUNFER, B.M. Seed-borne diseases and seed health testing of wheat. Copenhagen: Danish Government Institute of Seed Pathology for Developing Countries, 1993. 168p.

MERONUCK, R.A. The significance of fungi in cereal grains. Plant Disease, v.71, n.3, p.311-313, 1987.

MHETA, V.R.; BAIER, A. Variação patogênica entre isolados de Magnaporthe grisea atacando triticale e trigo no Estado do Paraná. Summa Phytopathologica, Piracicaba, v.24, v.2, p.119-125, 1998.

OLIVEIRA J.A.; VIEIRA, M.G.G.C.; VON PINHO, E.V.R.; CARVALHO, M.L.M. Comportamento de sementes de milho tratadas com fungicidas antes e após o armazenamento convencional. Revista Brasileira de Sementes, v.19, n.2, p.208-213, 1997.

OLIVEIRA, A.M.R.; BAIER, A.C. Qualidade industrial e resistência à helmintosporiose e à fusariose em triticale, trigo e centeio. Pesquisa Agropecuária Brasileira, v.28, n.5, p.603-608, 1993.

REIS, E.M. Caracterização dos fatores determinantes de epidemias de Gibberella zeae, em trigo. Passo Fundo: Embrapa-CNPT, 1990. 22p. EMBRAPA-PNP de trigo. Projeto 00485004/6 form.12.

REIS, E.M. Doenças do Trigo I; podridão-comum-dasraízes. Helmintosporiose. São Paulo: CNDA, 1988. 20p.

REIS, E.M.; CASA, R.T. Patologia de sementes de cereais de inverno. Passo Fundo, Aldeia Norte, 1998. 88p.

REUNIÃO DA COMISSÃO CENTRO-SUL BRASILEIRA DE PESQUISA DE TRITICALE, 10. Informações Técnicas das Comissões Centro-Sul Brasileira de Pesquisa de Trigo e de Triticale para a Safra de 2004. Londrina, IAPAR: Embrapa Soja, 2004. 214p.

ROCHA, J.A.G.; NEDEL, J.L.; BAIER, A.C. Teste de envelhecimento precoce para sementes de triticale (Triticosecale Wittmack). Revista Brasileira de Agrociência, v.4, n.3, p.206-210, 1998.

TUITE, J.; KOH-KNOX, C; STROCHINE, R.; CANTONE, F.A.; BAUMAN, L.F. Effect of physical damage to corn kernels on the development of Penicillium species and Aspergillus glaucus storage. Phytopathology, v.75, n.1, p.1137-1140, 1985.

TUITE, J.; SHANER, G.; EVERSON, R.J. Wheat scab in soft red winter wheat in Indiana in 1986 and its relation to some quality measurements. Plant Disease, v.74, n.9, p.959$962,1990$.

ZONTA, E.P.; MACHADO, A.A. Sistema de análise estatística para microcomputadores - SANEST. Pelotas: DMEC/IFM/UFPel, 1987. 